\title{
Accelerator-Based Irradiation Creep of Pyrolytic Carbon Used in TRISO Fuel Particles for the VHTR
}

\author{
(NERI Project 06-113) \\ AWARD NUMBER: DE-FC07-06ID14732
}

\section{Final Progress Report}

\author{
Lumin Wang (PI), Gary Was (co-PI), \\ Anne Campbell (Graduate Student) \\ Department of Nuclear Engineering \& Radiological Sciences \\ University of Michigan, Ann Arbor, MI 48109-2104
}

Pyrolytic carbon $(\mathrm{PyC})$ is one of the important structural materials in the TRISO fuel particles which will be used in the next generation of gas-cooled very-high-temperature reactors (VHTR). When the TRISO particles are under irradiation at high temperatures, creep of the PyC layers may cause radial cracking leading to catastrophic particle failure. Therefore, a fundamental understanding of the creep behavior of $\mathrm{PyC}$ during irradiation is required to predict the overall fuel performance.

The primary objective of this project is to characterize the creep behavior of PyC through a systematic program of accelerator-based proton irradiation and in-situ measurements under stress at various temperatures. It is expected that the test data will be analyzed to determine creep coefficients, which will then be correlated to existing coefficients measured under neutron irradiation.

This research project has been conducted for three and a half years. During this period, we have built and modified an apparatus that allows in situ measurement of creep behavior of thin specimen during proton beam irradiation at high temperature, tried hard to produce isotropic PyC thin foils that have the same structure as the PyC used in the TRISO fuel because the lack of external supply, conducted a series of in situ creep measurement during proton beam irradiation on the home made PyC and commercially acquired graphite, demonstrated the proof of concept, but failed to reach the original objective because the lack of proper sample material. The main hindrance of this project was the inability to produce PyC samples, in-house, that were of similar density and anisotropy as the PyC used in the TRISO fuel.

The details on the construction and modification of the research facility, production and characterization of the home-made $\mathrm{PyC}$ have been included in the fifteen previously submitted quarterly reports. The following is the detail of the most recent experimental results on commercially acquired graphite that demonstrated the proof of concept of the research approach.

Because the home made PyC foils are not completely isotropic and they are extremely brittle for handling during the previous experiments, a commercially available graphite grade that has similar material properties as PyC was acquired and used for the proof of concept experiemtn. These graphite samples were obtained from POCO Graphite Inc, and were EDM machined from 
grade EDM-AF5 graphite. The sample starting thickness was $70 \mu \mathrm{m}$, the initial width was $3 \mathrm{~mm}$, and the crystallite size is less than $1 \mu \mathrm{m}$.

\section{$\underline{\text { Irradiation Creep Experiment }}$}

\section{Experimental Procedure}

The experiment was performed with a $6 \mathrm{MPa}$ tensile stress applied to the sample, which allows for direct comparison with literature results [1]. The system was heated until the sample temperature reached $525^{\circ} \mathrm{C}$ and allowed to set for $\sim 72$ hours before the beam was applied. Throughout the experiment, the dimensional change of the stressed and reference sample were measured with the Laser Speckle Extensometer (LSE), the dimensional change of the stressed sample was also measured with the Linear Variable Differential Transformer (LVDT), sample temperature was measured with the two-dimensional infrared thermal imager, and the proton current was measured with a computer program in LabView. All of the measurements were recorded every 30 seconds and the complete set of data is shown in Figure 1. The stressed sample strain that was measured by the LSE is the blue data set, the reference sample strain measured by the LSE is the red data set, the stressed sample elongation measured by LVDT displacement is the green data set, the average sample temperature in the irradiated region is the black data set, and the proton current incident on the stage is the pink data set. The proton current can be converted into proton flux by

$$
\phi\left(\frac{p^{+}}{\mathrm{cm}^{2} s}\right)=\frac{I(\mu \mathrm{A}) 1 \times 10^{-6} \mathrm{C} / \mathrm{s}}{A\left(\mathrm{~cm}^{2}\right)} \frac{1 p^{+}}{1 \mu \mathrm{A}} \frac{1.602 \times 10^{-19} \mathrm{C}}{1}
$$

where $I$ is the current in $\mu \mathrm{A}$ measured by the LabView program. 


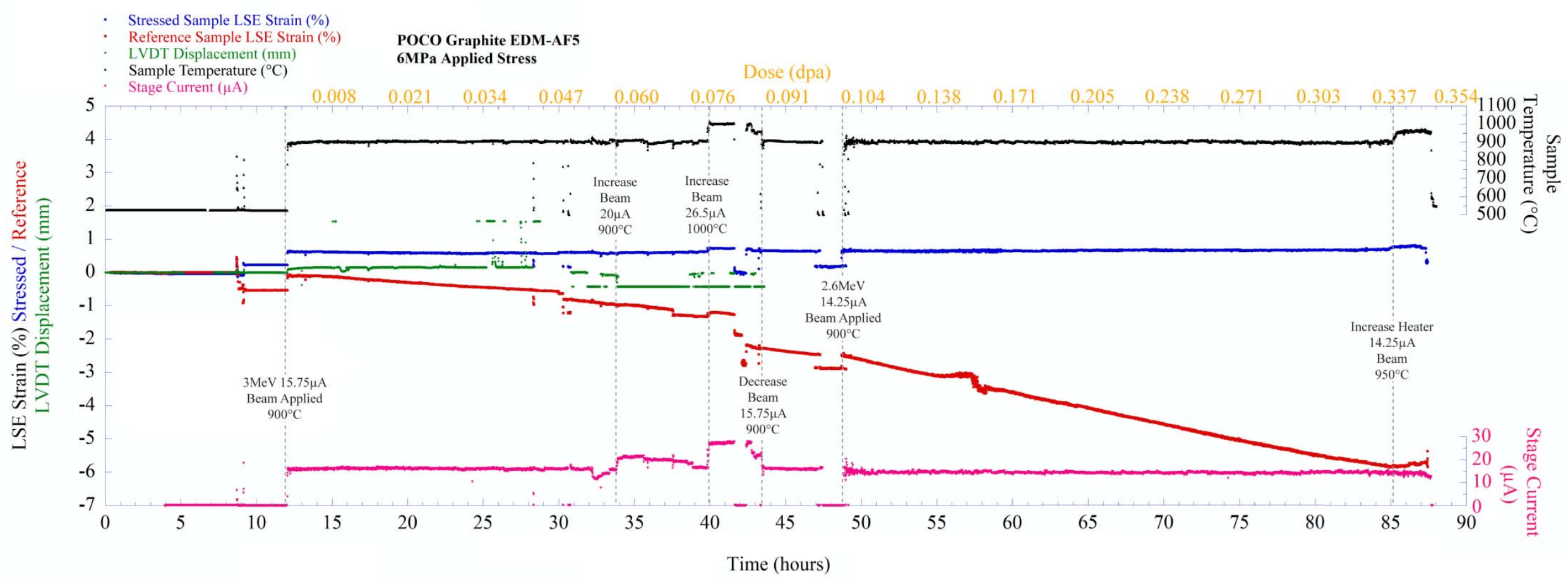

Figure 1: Raw experimental data showing stressed sample strain (red), reference sample strain (blue), LVDT displacement measurement for the stressed sample (green), sample temperature (black), and stage current (pink). 
Even before the irradiation portion of this experiment started there the surface texture of the graphite sample had a noticeable difference in the measurement from the LSE. The LSE patterns obtained from the graphite samples are much stronger than those we obtained with PyC. In prior experiments, with PyC, the LSE had AOI peak values of 15-20 and required restarts of the LSE software every 2-4 hours, but with the graphite samples the AOI peak values were consistently around 80-90 and the LSE only had to be restarted every 8-12 hours. Figure 2 shows two screen shots from the LSE, with the samples highlighted with red boxes. There is one difference between the graphite samples, Figure $2 \mathrm{a}$, and the PyC samples that requires mention, Figure $2 \mathrm{~b}$. The difference is how much of the laser light is scattered back to the LSE camera by the samples. The graphite samples have a rough surface that is more likely to scatter the laser light back to the LSE camera, which is a result of the EMD machining, while the PyC samples have a mirror-like surface and does not scatter as much light back to the camera. This difference in light scattering from the samples affects the camera setting, like exposure time and gain, needed to obtain speckle patterns. For the graphite samples the light scattering back from the samples is more than the light scattering back from the tantalum heater shield thus making the shield appear darker, but for the PyC samples the light scattered back from the samples is less than the amount of light scattering back from the heater shield thus making the heater shield appear brighter than the samples.

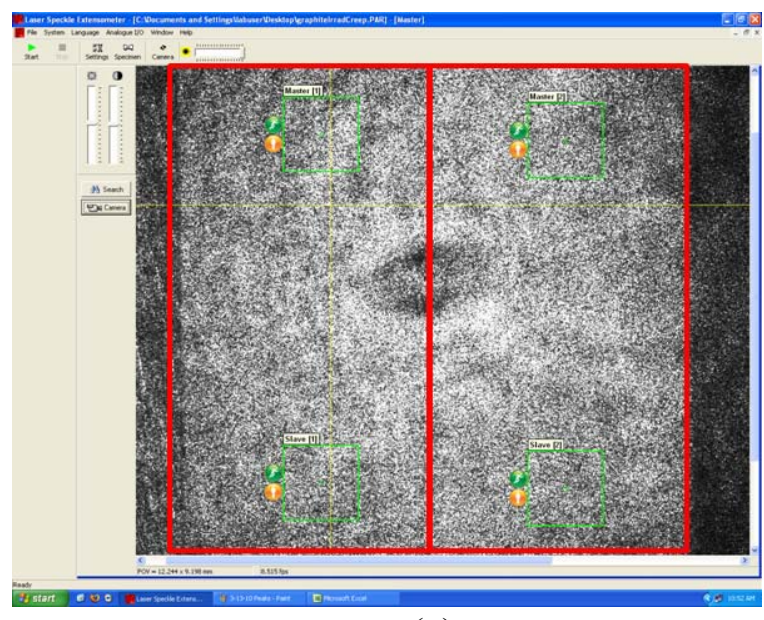

(a)

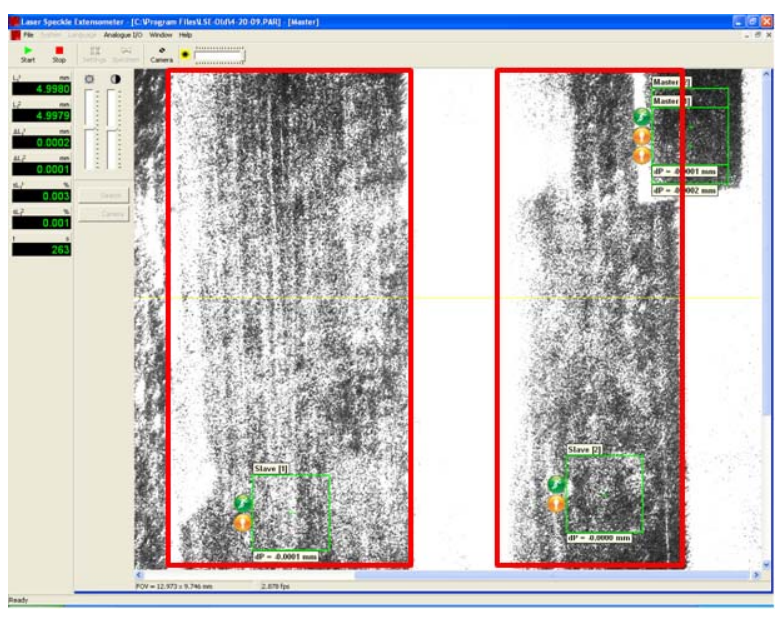

(b)

Figure 2: Comparison of LSE screen shot of (a) graphite and (b) PyC with only heat source coming from the stage.

The irradiation began with $15 \mu \mathrm{A}$ of current on the samples and a sample temperature of $900^{\circ} \mathrm{C}$. Immediately after putting the beam on the samples, there was an increase in brightness of the LSE image, but the LSE was able to continuously track elongation and contraction of the samples the instant the beam is applied. Figure 3 is a screen shot of the LSE software while tracking the graphite samples during the irradiation. The difference between Figure 3 and Figure $2 \mathrm{a}$ is that the heater shield is much brighter in Figure 3, which is due to the heater shield being irradiated by the protons. 


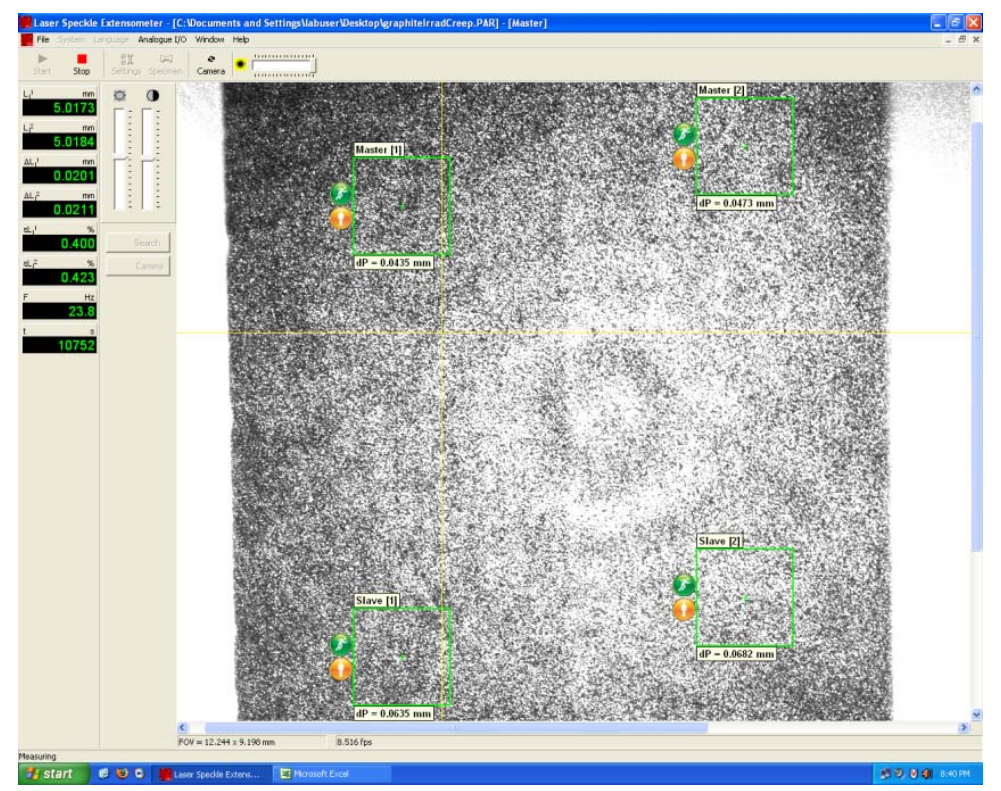

Figure 3: Screen shot of LSE program taken during irradiation between hours 12-30.

It was desired to increase the dose rate from $0.062 \mathrm{dpa} /$ day to $0.20 \mathrm{dpa} / \mathrm{day}$. This was to be accomplished by increasing the proton current from $15 \mu \mathrm{A}$ to $50 \mu \mathrm{A}$, but due to the amount of sample heating that comes from the beam a current of only $20 \mu \mathrm{A}$ was attained while still keeping the sample temperature at $900^{\circ} \mathrm{C}$, which required reducing the back heater until less than $20 \%$ of the irradiated region heating was from the stage heater. The decrease in percent heating from the stage heater caused the temperature profile along the irradiated region to become non-uniform, and also resulted in beam current changes of less than $0.25 \mu \mathrm{A}$ affected the temperature of the irradiation region by at least $15^{\circ} \mathrm{C}$. Figure 4 shows the change in uniformity of the temperature profile along the length of the stressed sample when $50 \%$ of the heating came from the stage heater (blue) and less than $20 \%$ of the heating came from the stage heater (red). 


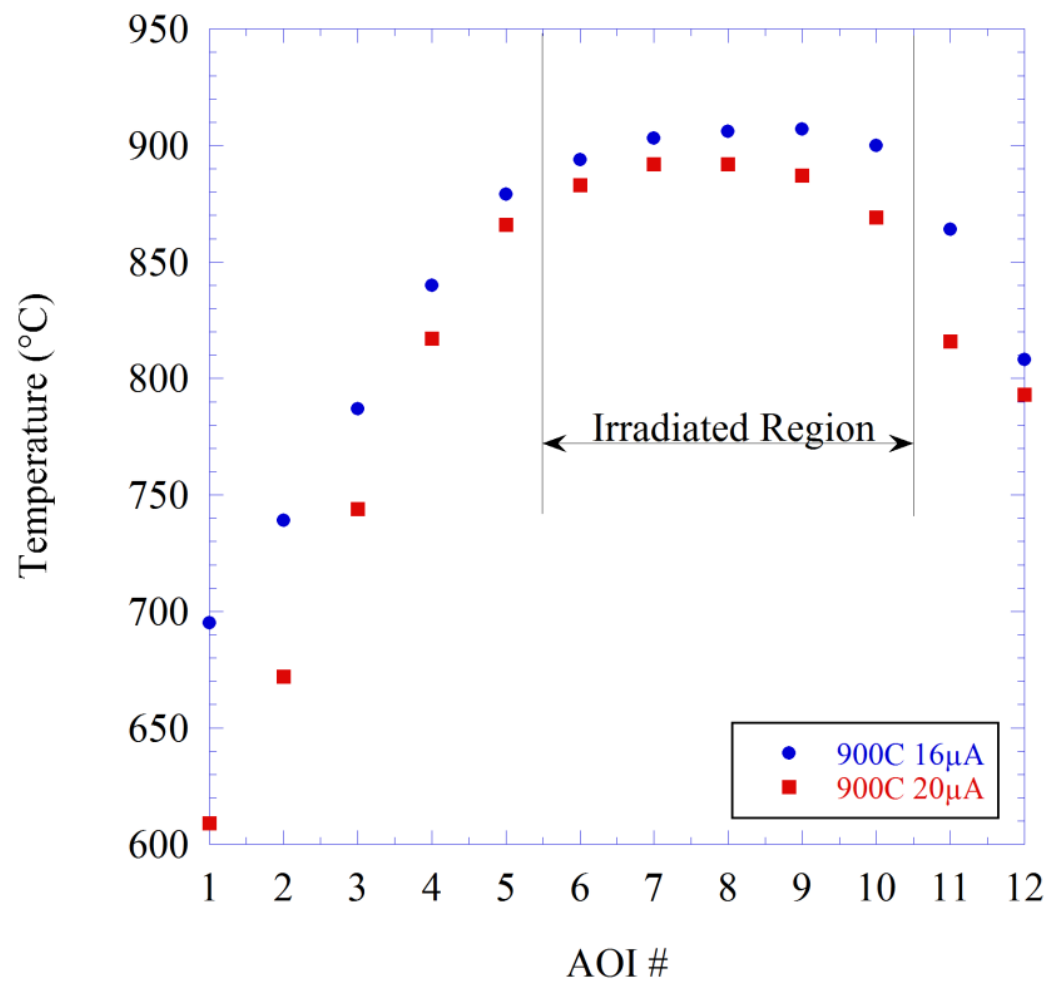

Figure 4: Temperature profile through stressed sample, showing the uniformity of sample temperature in the stressed sample with $50 \%$ of the heating from the stage heater (blue) and with less than $20 \%$ heating coming from the stage heater (red).

After the irradiation had progressed for 20 hours, the LVDT stopped recording elongation. Since the LSE was still tracking the samples it was decided to continue the experiment, but it became imperative that the conditions be kept at parameters where the LSE could still track the samples. After determining that operating at high proton currents, while still keeping the irradiation temperature at $900^{\circ} \mathrm{C}$ was not possible the stage current was increased to $26.5 \mu \mathrm{A}$, which increased the sample temperature to $1000^{\circ} \mathrm{C}$. The experiment was kept at these setting for only 2 hours because the LSE image became saturated, the AOI peak values dropped to 10-15, and the LSE required restarts every 2 hours. At this point the stage current was decreased to $23 \mu \mathrm{A}$ which decreased sample temperature to $950^{\circ} \mathrm{C}$, but the LSE was still showing saturation and requiring frequent restarts. Thus the experimental settings were returned to $900^{\circ} \mathrm{C}$ and $15.75 \mu \mathrm{A}$ on the stage.

During the irradiation, the accelerator unexpectedly shut down. During hours 28-41 there were three tank sparks that damaged some diodes in the accelerator high voltage supply. This prevented the accelerator from continuing to operate at $1.5 \mathrm{MV}$, but it was still able to operate at $1.3 \mathrm{MV}$ so the experiment continues with proton energy of $2.6 \mathrm{MeV}$. A $2.6 \mathrm{MeV}$ proton beam, with current of $14.25 \mu \mathrm{A}$, was applied to the samples, which returned the sample temperature to $900^{\circ} \mathrm{C}$.

The final test performed during this experiment was to determine what sample temperature could be achieved by increasing the heating from the stage heater. This we performed by leaving the proton beam current at $14.25 \mu \mathrm{A}$ and increasing the stage heater current from $5.4 \mathrm{~A}$ to $7 \mathrm{~A}$. This 
increase was found to only cause a $60^{\circ} \mathrm{C}$ increase in sample temperature. This $60^{\circ} \mathrm{C}$ increase in temperature was sufficient to cause saturation of the LSE. After this test was performed the experiment was ended because the experimental conditions were being severely limited by the loss of the LVDT measurement.

\section{$\underline{\text { Results and Discussion }}$}

Figure 5 is a plot of the LSE measured elongation data for the stressed sample. During the first 25 hours of irradiation the noise in the LSE measurements makes it impossible to determine a creep rate. After the beam energy was decreased to $2.6 \mathrm{MeV}$ the dose rate increased by a factor of 2.55 and there was a noticeable elongation of the sample. From hours 49 through 80 the linear fit of the elongation resulted in a slope of $7.096 \times 10^{-4} \% /$ hour $^{-1}$ or $1.971 \times 10^{-9} \mathrm{~s}^{-1}$. The linear fit is shown in Figure 5 as the orange line, and the 95\% confidence interval is bound by the green and red lines.

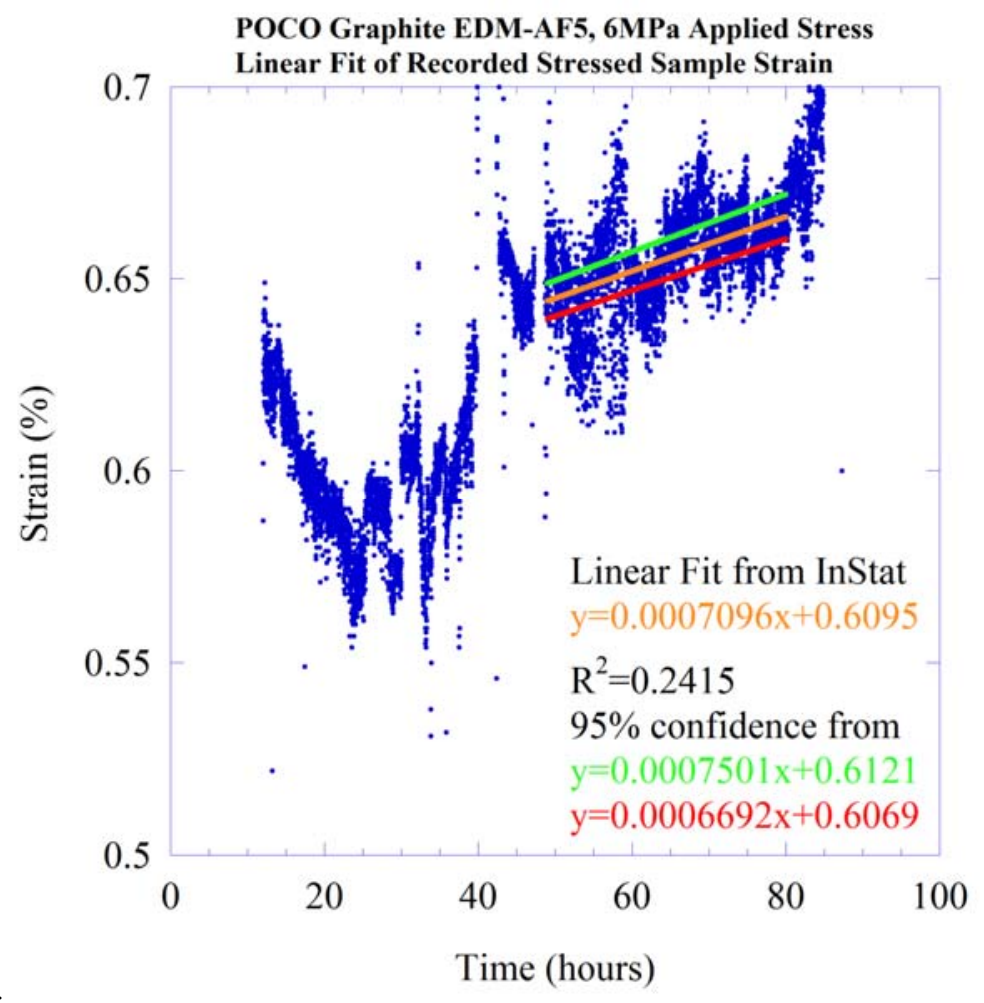

Figure 5: Plot of elongation data of the stressed sample.

Previous experiments have found that there is an inherent noise of $\pm 0.02 \%$ in the LSE measurements. This noise has an effect on the minimum creep rate that can be discerned from the LSE data. The linear fit in Figure 5 is for data measured over 31 hours. If the $\pm 0.02 \%$ of the LSE data were to result in measurement from $-0.02 \%$ to $0.02 \%$ over this time range, the maximum creep rate that could erroneously measured would be $1.29 \times 10^{-3} \% / \mathrm{hr}$ or $3.58 \times 10^{-9} \mathrm{~s}^{-1}$. From this possible error, it cannot be stated if the linear fit performed from hours 49-80 is from creep experienced by the sample or from inherent noise in the LSE.

One positive outcome from this experiment is that the contraction of the reference sample was measured with the LSE. The contraction measurement is plotted in Figure 6. Also included in 
Figure 6 is the linear fit of the data when the LSE was tracking well and the irradiation parameters were stable for multiple hours. The blue linear fit is for the contraction of the sample when irradiated at $900^{\circ} \mathrm{C}$ with a $3 \mathrm{MeV}$ proton beam, and the green linear fit is contraction when irradiated at $900^{\circ} \mathrm{C}$ with a $2.6 \mathrm{MeV}$ proton beam. The contraction rate of the reference sample during the $3 \mathrm{MeV}$ irradiation is $-8.086 \times 10^{-8} \mathrm{~s}^{-1}$ and the contraction rate during the $2.6 \mathrm{MeV}$ irradiation is $-2.696 \times 10^{-7} \mathrm{~s}^{-1}$. The final dose of the samples is $0.354 \mathrm{dpa}$. Neutron irradiation experiments measure contraction of graphite when irradiated without an applied stress.

Figure 7 is a plot of contraction data reported in literature [2] for $\mathrm{H}-451$ graphite that was irradiated at $900^{\circ} \mathrm{C}$, both parallel (blue) and perpendicular (red) to the extrusion direction, and the contraction of the sample during this experiment (green). By using the final dose of the proton irradiation the contraction rate of the reference sample can be compared with the contraction of graphite presented in literature. The contraction rates for graphite from the literature are $-0.111 \%$ /dpa and $-0.190 \%$.dpa from zero to $2 \mathrm{dpa}$, while the contraction rate for the reference sample from this experiment is $-14.47 \% / \mathrm{dpa}$. The contraction rate calculated from the reference sample is two orders or magnitude larger than the values reported in literature. One possible source of this difference is the measurement method. The measurement from literature was measured outside the reactor after the sample had been brought back to room temperature, while the proton measurements were performed during the experiment while at temperature.

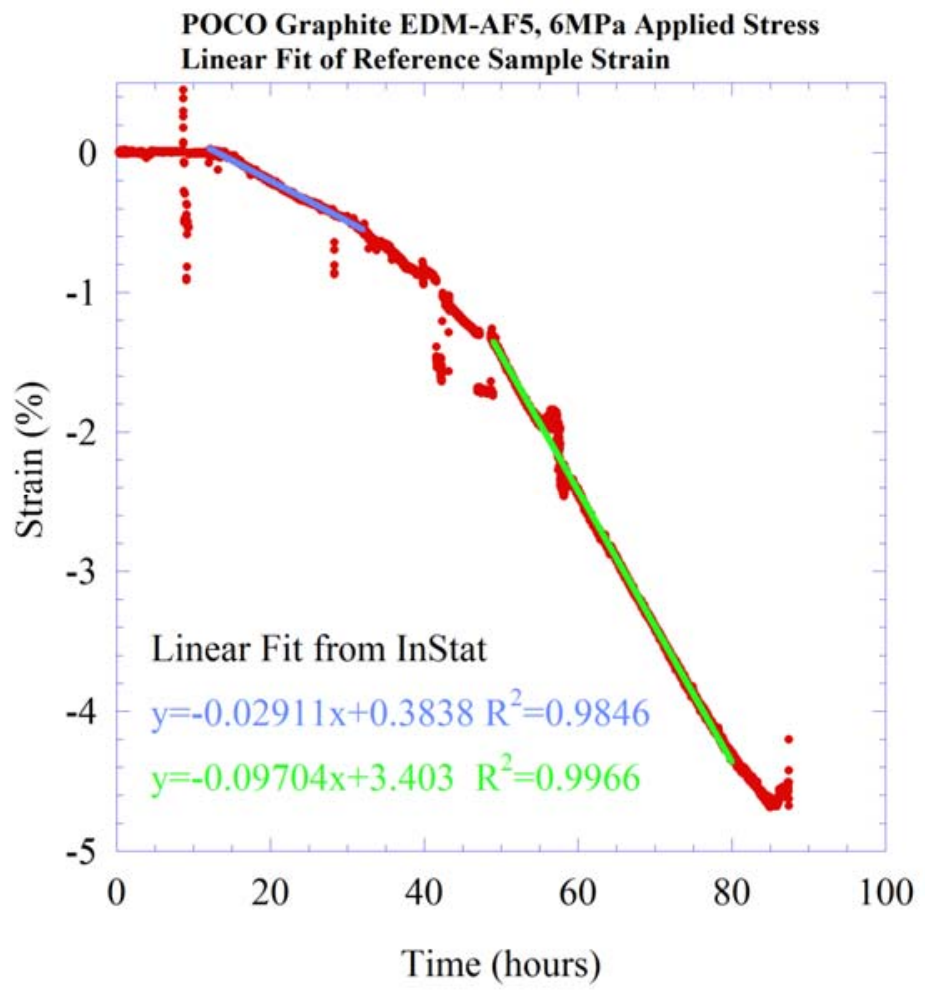

Figure 6: Plot of contraction data for reference sample. 


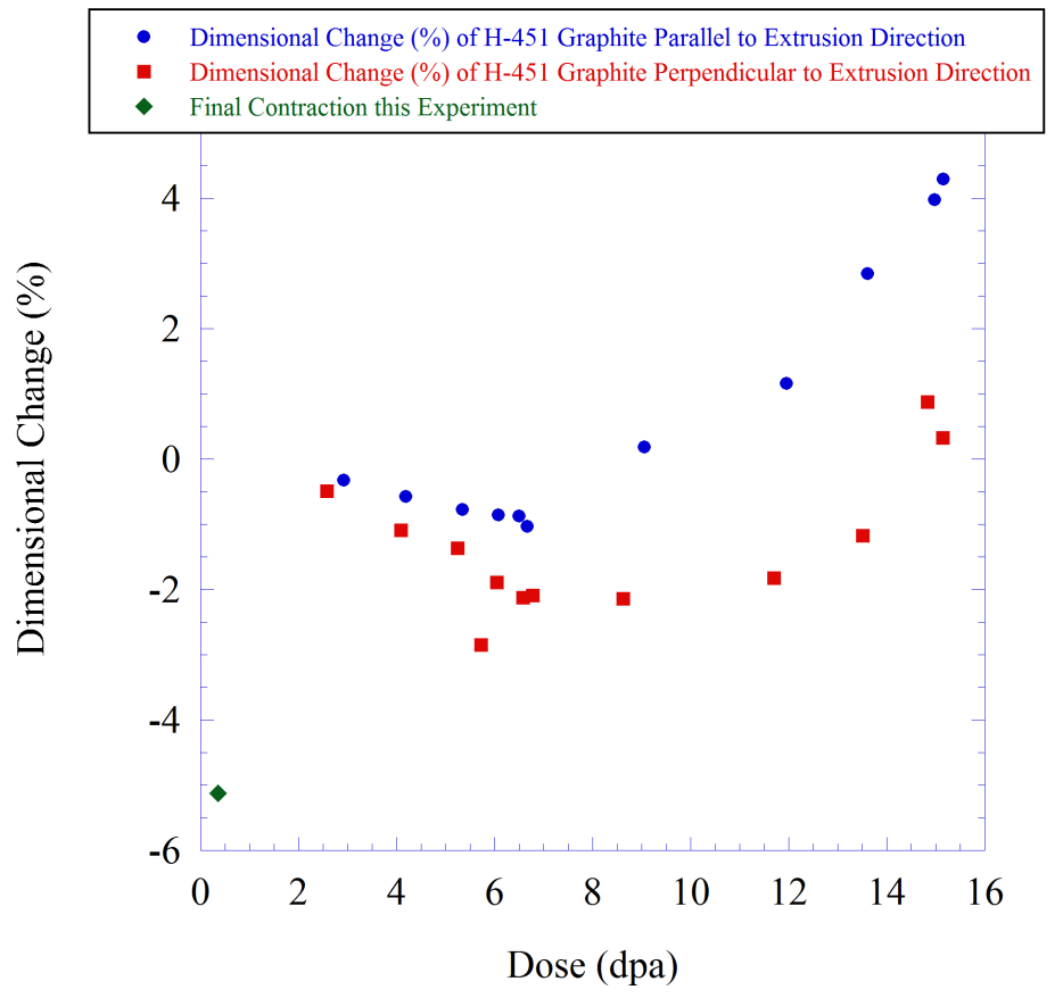

Figure 7: Literature data [2] of unrestrained graphite contraction for $\mathrm{H}-451$ graphite irradiated at $900^{\circ} \mathrm{C}$.

The other analysis that has been performed is to determine the true strain of the stressed sample. The true strain of the stressed sample is the measured strain of the stressed sample minus the contraction strain of an unstressed sample irradiated at similar conditions. Because the LSE was simultaneously recording the dimensional changes of the stressed and reference sample, the calculation of true strain was accomplished by subtracting the reference sample dimensional change from the stressed sample dimensional change. The true strain of the stressed sample is plotted in Figure 8. The purple linear fit is for the true strain of the sample when irradiated at $900^{\circ} \mathrm{C}$ with a $3 \mathrm{MeV}$ proton beam, and the orange linear fit is the true strain when irradiated at $900^{\circ} \mathrm{C}$ with a $2.6 \mathrm{MeV}$ proton beam. The true creep rate during the $3 \mathrm{MeV}$ irradiation is $7.555 \times 10^{-8} \mathrm{~s}^{-1}$ and the true creep rate during the $2.6 \mathrm{MeV}$ irradiation is $2.690 \times 10^{-7} \mathrm{~s}^{-1}$. The true creep rates convert into steady state creep constants by using the conversion

$$
k\left(\frac{n}{c m^{2}} P a\right)^{-1}=\frac{\dot{\varepsilon}\left(s^{-1}\right)}{\dot{d}\left(\frac{d p a}{d a y}\right) * \frac{1 d a y}{86400 s}} * \frac{6.8 d p a}{1 \times 10^{22} \frac{n}{c m^{2}}} * \frac{1}{\sigma(P a)} .
$$

The resulting steady state creep coefficients determined in this experiment are $4.655 \times 10^{-}$ ${ }^{30}\left(\mathrm{n} / \mathrm{cm}^{2} * \mathrm{~Pa}\right)^{-1}$ during the $3.0 \mathrm{MeV}$ irradiation and $16.59 \times 10^{-30}\left(\mathrm{n} / \mathrm{cm}^{2} * \mathrm{~Pa}\right)^{-1}$ during the $2.6 \mathrm{MeV}$ irradiation. These values are comparable with the steady state creep coefficient reported for $\mathrm{H}-$ 451 graphite at $900^{\circ} \mathrm{C}$ of $0.37 \times 10^{-29}\left(\mathrm{n} / \mathrm{cm}^{2} * \mathrm{~Pa}\right)^{-1}[3]$. 


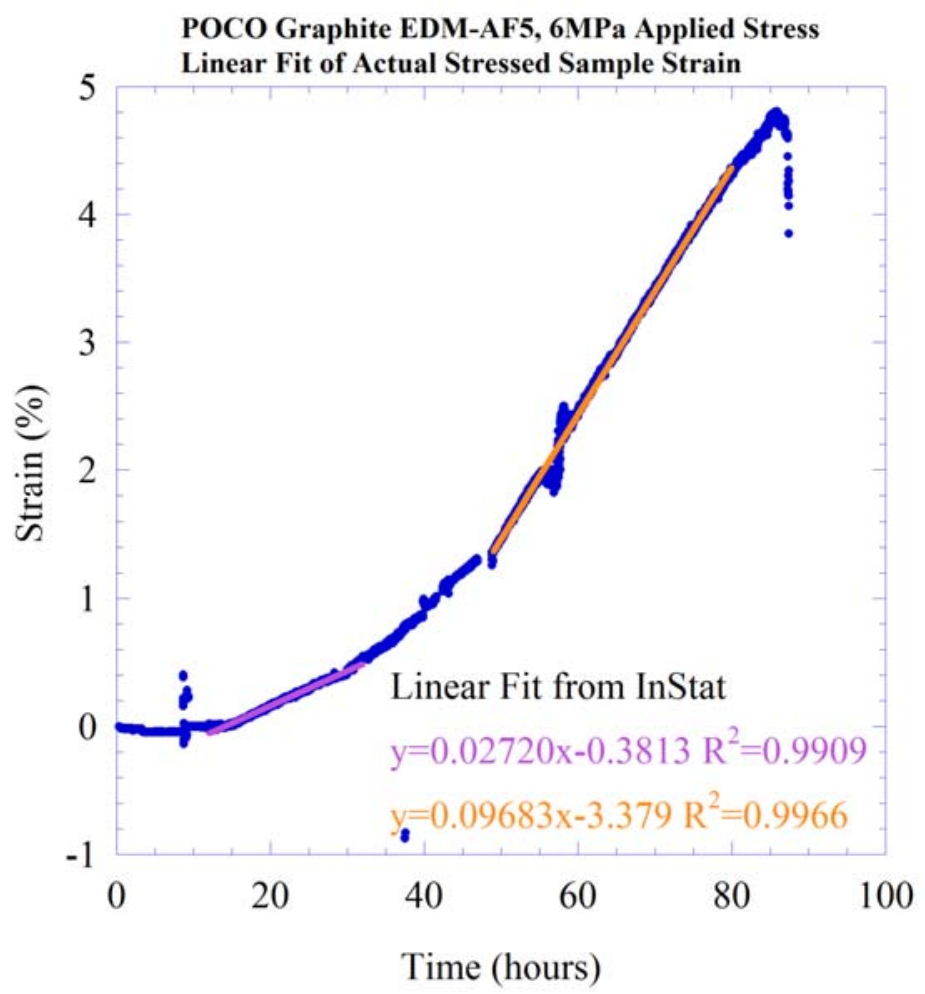

Figure 8: Plot of true strain of stressed sample, where the true strain is defined as the measured strain minus the contraction of the reference sample.

\section{Damage Calculation for Different Proton Energy}

During the irradiation the beam energy had to be decreased from $3 \mathrm{MeV}$ to $2.6 \mathrm{MeV}$ due to problems with the accelerator high voltage supply. A SRIM calculation was performed with $2.6 \mathrm{MeV}$ protons into $1.9 \mathrm{~g} / \mathrm{cm}^{3}$ dense carbon and is compared to the calculation for $3 \mathrm{MeV}$ protons. Figure 9 shows the SRIM damage calculations for both proton energies. 


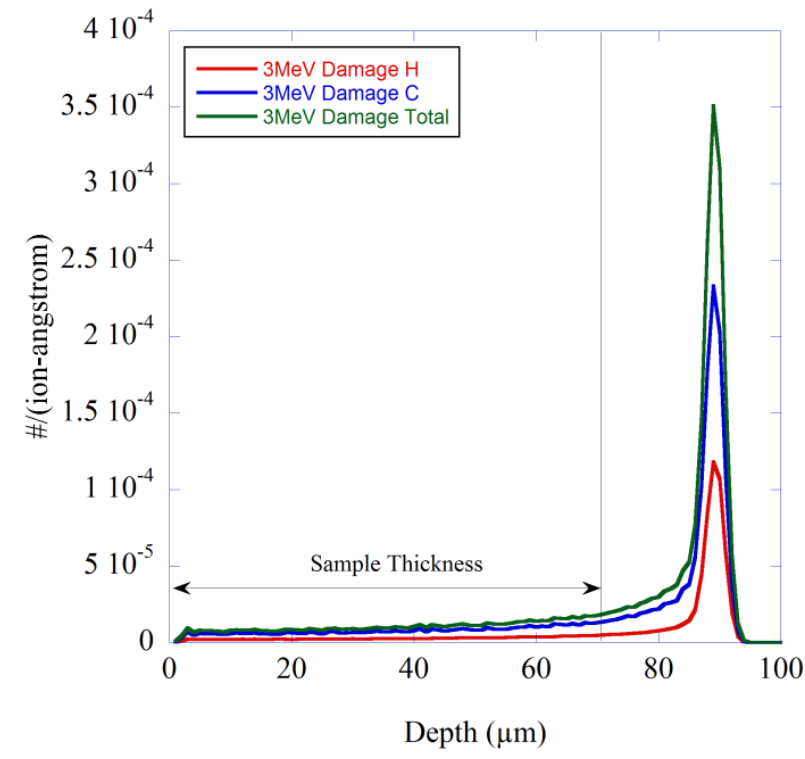

(a)

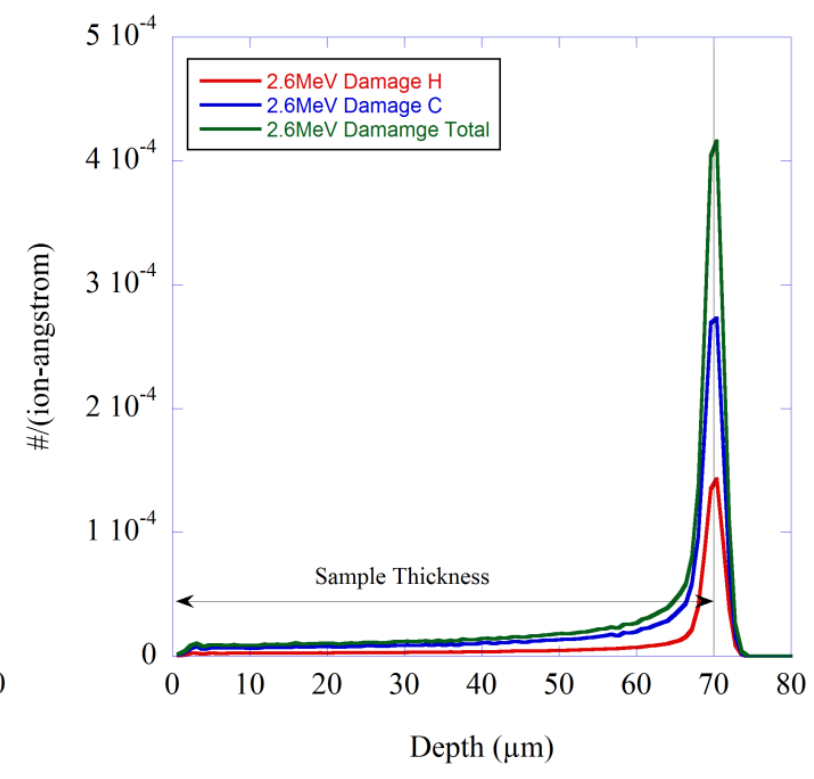

(b)

Figure 9: SRIM damage calculations for (a) $3 \mathrm{MeV}$ protons and (b) $2.6 \mathrm{MeV}$ protons into $1.9 \mathrm{~g} / \mathrm{cm} 3$ carbon.

For the $2.6 \mathrm{MeV}$ protons the damage profile through the sample begins to increase near the back of the sample so the average dose of the sample must be calculated. This has been done by numerically integrating the damage peak and then dividing by sample thickness using

$$
\text { damage }=\frac{\sum_{i=1}^{j} d(i) *(t(i)-t(i-1))}{70 \mu m} .
$$

This method resulted in a thickness averaged damage rate of $1.05 \times 10^{-5} \# /$ (ion-angstrom) for $3 \mathrm{MeV}$ protons in $1.9 \mathrm{~g} / \mathrm{cm}^{3}$ density graphite, and a thickness averaged damage rate of $2.99 \times 10^{-5} \# /$ (ion-angstrom) for $2.6 \mathrm{MeV}$ protons in the same sample. During the irradiation with $3 \mathrm{MeV}$ the stage current was kept around $15.75 \mu \mathrm{A}$, which resulted in a damage rate of $0.0616 \mathrm{dpa}$ /day. During the irradiation with $2.6 \mathrm{MeV}$ protons the stage current was kept around $14.25 \mu \mathrm{A}$, which resulted in a damage rate of $0.159 \mathrm{dpa} /$ day.

\section{$\underline{\text { Summary }}$}

Our most recent experiment has shown initial proof-of-concept that proton irradiation-induced creep experiments can be performed on a material similar to PyC for the TRISO fuel. Because PyC similar to the layers in the TRISO fuel was not available a similar microstructure POCO graphite grade was used instead. This experiment proved that in-situ dimensional change can be measured concurrently for both the stressed sample and the unstressed reference sample. The LSE was used to measure elongation of the stressed sample and contraction of the reference 
sample. Unfortunately higher dose rates and temperatures were not sustainable because the LVDT failed and the LSE could not track elongation at these settings. The next experiment should be performed with a higher stress and with higher temperatures and dose rates as long as the LVDT and LSE are working correctly and recording elongation.

\section{$\underline{\text { Future Work }}$}

We have planned to continue the irradiation creep experiment on the POCO graphite at varying temperatures and dose rates with an applied tensile stress of 20.7MPa. This stress level will allow for more direct comparisons with experimental results from compressive creep experiments performed with the same stress on H-451 graphite. After the samples have been used in the irradiation creep experiments, microstructural analysis will be performed to understand how the sample density, anisotropy, and crystal structure changed.

We will be ready to conduct the in situ creep measurement on PyC during proton ion irradiation at varies temperatures when the samples that have the same structure and property as the PyC used in the TRISO fuel become available.

\section{References}

1. Burchell, T.D., "Irradiation Induced Creep Behavior of H-451 Graphite" Journal of Nuclear Materials, 381, (2008), 46-54.

2. Snead, L.L., T.D. Burchell, and Y. Katoh, "Swelling of Nuclear Graphite and High Quality Carbon Fiber Composite under Very High Irradiation Temperature" Journal of Nuclear Materials, 381, (2008), 55-61.

3. Burchell, T. and R. Bratton, Physically Based Models of the Behavior of Nuclear Graphite under Neutron Irradiation. 2005. 